\title{
Palonosetron versus ondansetron for prevention of nausea and vomiting after total abdominal hysterectomy under spinal anesthesia with intrathecal morphine: a double-blind, randomized controlled trial
}

Guilherme Oliveira Campos ${ }^{1,2^{*}}$ (D), Marcelo de Jesus Martins ${ }^{3}$, Gabriel Nascimento Jesus ${ }^{1,4}$,

Paulo Roberto Rios de Oliveira ${ }^{5}$, Caio Nogueira Lessa ${ }^{5}$, João Carlos Macêdo Fernandes de Oliveira Junior ${ }^{1}$, Lucas Jorge Santana de Castro Alves ${ }^{6}$, Rodrigo Leal Alves ${ }^{1,4}$ and Norma Sueli Pinheiro Módolo ${ }^{3}$

\begin{abstract}
Background: Hysterectomy is a widely performed surgery and neuraxial anesthesia with intrathecal morphine provides superior quality of recovery. Postoperative nausea and vomiting (PONV) is a frequent problem with intrathecal morphine use. Although palonosetron is effective for prevention of PONV after general anesthesia, its efficacy after neuraxial anesthesia has not been established. This study was conducted to compare the use of palonosetron with ondansetron for PONV prophylaxis in patients at a high risk of PONV during total abdominal hysterectomy (TAH) under spinal anesthesia with intrathecal morphine.

Methods: This prospective, randomized double-blind study conducted at São Rafael Hospital involved 140 American Society of Anesthesiologists physical status I or II women who underwent TAH under spinal anesthesia with intrathecal morphine and who had at least 3 risk factors for PONV based on Apfel's simplified score. The patients were randomized into two groups: one received palonosetron whereas the other received ondansetron. All patients received spinal anesthesia with intrathecal morphine, as well as dexamethasone plus palonosetron or ondansetron for PONV prophylaxis. The overall incidence of PONV, incidence of early- and late-onset nausea and vomiting, severity of nausea, and use of rescue antiemetics were recorded.
\end{abstract}

Results: The overall incidence of PONV was $42.9 \%$ in the palonosetron group and 52.9\% in the ondansetron group $(p>0.05)$. No significant differences existed in the incidence of early- and late-onset nausea or early-onset vomiting between the two groups. The incidence of late-onset vomiting was significantly lower in the palonosetron group. Conclusions: Palonosetron exhibited efficacy similar to that of ondansetron for reducing the overall incidence of PONV after TAH under spinal anesthesia with intrathecal morphine; however, palonosetron reduced the incidence of late-onset vomiting significantly better than ondansetron.

Trial registration: RBR-4gnm8n (ensaiosclinicos.gov.br), date of registration: August 18, 2014.

Keywords: Antiemetics, Morphine, Ondansetron, Postoperative nausea and vomiting, Spinal anesthesia

\footnotetext{
* Correspondence: guioliveiracampos@gmail.com

'Department of Anesthesiology, São Rafael Hospital, D'Or Institute for

Research and Education (IDOR), Salvador, Brazil

${ }^{2}$ Department of Anesthesiology, Cardiopulmonar Hospital, Salvador, Brazil

Full list of author information is available at the end of the article
}

(c) The Author(s). 2019 Open Access This article is distributed under the terms of the Creative Commons Attribution 4.0 International License (http://creativecommons.org/licenses/by/4.0/), which permits unrestricted use, distribution, and reproduction in any medium, provided you give appropriate credit to the original author(s) and the source, provide a link to the Creative Commons license, and indicate if changes were made. The Creative Commons Public Domain Dedication waiver (http://creativecommons.org/publicdomain/zero/1.0/) applies to the data made available in this article, unless otherwise stated. 


\section{Background}

Postoperative nausea and vomiting (PONV) is a common perioperative complication that is associated with clinical and economic consequences, including wound dehiscence, delayed nutrition, prolonged hospital stay, and reduced patient satisfaction. Despite advances in prevention and treatment, the incidence of PONV remains high, especially in high-risk patients [1].

Total abdominal hysterectomy (TAH) is a surgery that is often performed worldwide, and neuraxial anesthesia with intrathecal morphine has been shown to provide improved quality of recovery because of superior, prolonged pain control after TAH [2]. However, PONV is a frequent complication after TAH due to both the effects of intrathecal morphine and the intrinsic characteristics of the patients [3-7].

Palonosetron is a second generation 5HT-3 receptor antagonist that has a greater binding affinity and a longer plasma half-life than other drugs in the same class $[8,9]$. Studies have reported the superiority of palonosetron relative to other $5 \mathrm{HT}-3$ receptor antagonists for the prevention of PONV in patients undergoing general anesthesia. However, little is known regarding the ability of palonosetron to prevent PONV after spinal anesthesia [10-12].

The aim of the current study was to compare the efficacy of palonosetron versus ondansetron, both in combination with dexamethasone, for PONV prophylaxis in patients undergoing TAH under spinal anesthesia with intrathecal morphine.

\section{Methods}

This study was approved by the Research Ethics Committee (1.238.882/2015) of São Rafael Hospital, a tertiary care hospital in Salvador, Brazil. The trial was conducted from January to October of 2015, in adherence with the Consolidated Standards of Reporting Trials (CONSORT) guidelines, and was registered with the Brazilian Clinical Trial Registry (RBR-4gnm8n, August 18, 2014).

After they had provided written informed consent, 175 consecutive female patients scheduled to undergo elective TAH were recruited for this prospective, randomized, double-blinded study. The inclusion criteria were age 18 to 65 years, American Society of Anesthesiologists physical status I or II, and at least 3 risk factors for PONV as determined by Apfel's simplified risk score. Exclusion criteria were body mass index $>35$, contraindications to spinal anesthesia, use of corticosteroids or antiemetic medications in the $24 \mathrm{~h}$ preceding the surgery, and allergy to any medication used in the study protocol.

After enrollment, patients were randomly assigned in a 1:1 ratio to receive either ondansetron or palonosetron. The group assignment was presented in opaque sealed envelopes to a pharmacist who was not involved in the study. Randomization was performed with a block size of 6 using a central web-based system. A nurse who was not involved in the study opened the envelopes and prepared the medications as injectable solutions of either palonosetron $0.075 \mathrm{mg}$ or ondansetron $4 \mathrm{mg}$, both diluted in normal saline to a total volume of $2 \mathrm{~mL}$, in identical syringes. The study drug was administered intravenously (i.v.) immediately after the spinal block.

Preoperative fasting was initiated at midnight for all patients, and none received premedication. After arrival in the operating room, standard monitoring was applied (electrocardiography, pulse oximetry, and a non-invasive blood pressure cuff) and the subjects received $10 \mathrm{~mL} / \mathrm{kg}$ of lactated Ringer's solution i.v., $2 \mathrm{mg}$ midazolam i.v., and $50 \mu \mathrm{g}$ fentanyl i.v.

The patients were then placed in a sitting position, and a spinal block was performed at the L3-L4 or L4L5 interspace using a 27-gauge Sprotte needle, followed by intrathecal injection of $15 \mathrm{mg}$ hyperbaric bupivacaine and $100 \mu \mathrm{g}$ preservative-free morphine. An appropriate block level (T6 dermatome) was confirmed prior to skin incision. Patients in both groups received additional titrated doses of midazolam (up to $10 \mathrm{mg}$ i.v.) to maintain a level of sedation between -1 and -3 on the Richmond Agitation-Sedation Scale (0 for alert and calm, -5 for unarousable). Ephedrine $5 \mathrm{mg}$ i.v. was titrated to maintain an arterial blood pressure within $20 \%$ of baseline. Atropine $0.5 \mathrm{mg}$ i.v. was given as needed to maintain a heart rate above 50 beats per minute.

Considering the high risk of PONV and ethical issues, all patients received dexamethasone $8 \mathrm{mg}$ i.v. just after placement of the i.v. catheter as part of the PONV prophylaxis regimen. For postoperative analgesia, all patients received a multimodal regimen consisting of ketoprofen $100 \mathrm{mg}$ i.v. every $8 \mathrm{~h}$ and metamizole $2 \mathrm{~g}$ i.v. every $6 \mathrm{~h}$, beginning in the operating room. Morphine 3 mg i.v. up to every $4 \mathrm{~h}$ was used if the patient's pain score was greater than 4 on the visual analog scale (VAS; $0=$ no pain, $10=$ the worst pain imaginable). Patients were observed in the post-anesthesia care unit for at least $1 \mathrm{~h}$ after surgery before they were transferred to the ward.

The incidence of PONV, severity of nausea, and the use of rescue antiemetics were evaluated at $1,6,24$, and $48 \mathrm{~h}$ after surgery. An episode of vomiting was defined as either vomiting (expulsion of stomach contents) or retching (involuntary attempt to vomit that did not expel stomach contents). Severity of nausea was assessed using a VAS ranging from 0 to $10(0=$ no nausea, $10=$ worst nausea imaginable). Rescue antiemetics (metoclopramide 10 mg i.v. followed by ondansetron $4 \mathrm{mg}$ i.v. if there was no response to metoclopramide) were administered upon the patient's request or with the onset of vomiting.

A simplified PONV impact scale questionnaire consisting of two questions was administered to all patients 
just before hospital discharge. A score from 0 to 6 was derived based the patient's answers to the questions and scores above 4 were considered to indicate clinically significant PONV [13]. Patients were also asked to rate their experience regarding the management of PONV on a 4point scale (poor, average, good, or excellent). Adverse events, such as dizziness and headache, were also investigated and recorded during the 48-h observation period.

The primary outcome measured was the incidence of PONV during the entire observation period. Secondary outcomes included the incidence of either nausea or vomiting, severity of nausea, use of rescue antiemetics, incidence of clinically important PONV, and overall patient satisfaction with the management of PONV. Earlyonset nausea and/or vomiting were considered to occur within the first $6 \mathrm{~h}$ after surgery, whereas late-onset nausea and/or vomiting were considered to occur between 6 and $48 \mathrm{~h}$ after surgery.

In order to calculate the sample size, we conducted a retrospective review of the incidence of PONV in patients who had undergone TAH in the preceding year at São Rafael Hospital. A PONV incidence rate of approximately $60 \%$ was observed in patients who received ondansetron and dexamethasone in the operating room. It was estimated that a sample size of 67 patients per group would achieve $80 \%$ power for the detection of a $40 \%$ reduction in the incidence of PONV in the palonosetron group with an alpha error of 5\% [14]. To account for patient dropout, we randomized 70 patients to each group.

The analysis was performed on an intention-to-treat basis using data from all randomized patients who underwent TAH. Dichotomous variables are expressed as relative and absolute frequencies. As the continuous variables in the study did not yield normal distributions, they are expressed as medians and interquartile ranges, as were the ordinal variables. The non-parametric Mann-Whitney test was used to compare data derived from continuous and ordinal variables in the two groups. Dichotomous variables were analyzed using the $\chi^{2}$ test or Fisher's exact test as appropriate, and $P<0.05$ was considered statistically significant. Statistical analysis was performed using SPSS for Windows (version 14, SPSS Inc., Chicago, IL, USA).

\section{Results}

Of the 175 patients who were initially screened, 140 met the inclusion and exclusion criteria and were randomly assigned to a study group. All patients who underwent randomization completed the trial, and there were $70 \mathrm{pa}-$ tients in each group (Fig. 1). The groups were well matched for age, height, body mass index, clinical comorbidities, smoking status, and preoperative fasting time. There were no significant differences in the duration of anesthesia, volume of infused crystalloid, total dose of midazolam, or use of vasopressors or atropine (Table 1).

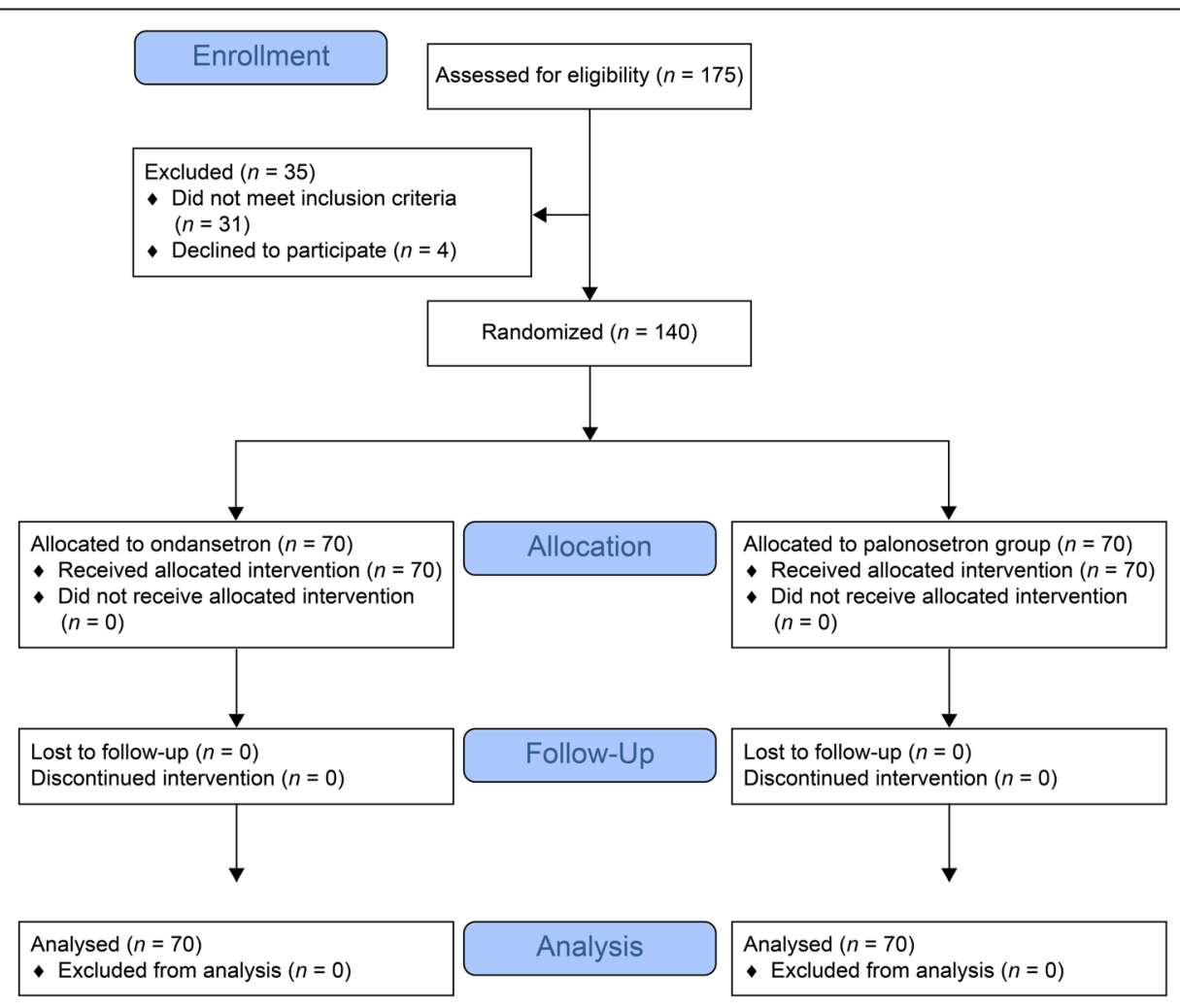

Fig. 1 CONSORT flow diagram 
Table 1 Characteristics, anesthetic, and surgical data of patients in the ondansetron and palonosetron groups

\begin{tabular}{llll}
\hline & Ondansetron & Palonosetron & $P$ value \\
\hline Age (years) & $44(41 / 47)$ & $45(42 / 48)$ & 0.334 \\
Weight $(\mathrm{kg})$ & $68.4 \pm 10.7$ & $70.3 \pm 12.0$ & 0.317 \\
Height $(\mathrm{cm})$ & $158 \pm 6$ & $159 \pm 5$ & 0.609 \\
Body mass index $\left(\mathrm{kg} / \mathrm{m}^{2}\right)$ & $27.2 \pm 3.9$ & $27.7 \pm 4.0$ & 0.453 \\
Motion sickness/ & $7.1 \%$ & $5.7 \%$ & 0.730 \\
previous PONV & & & \\
Smoking & $0 \%$ & $1.4 \%$ & 1.000 \\
Hypertension & $22.8 \%$ & $27.1 \%$ & 0.558 \\
$\begin{array}{l}\text { Diabetes mellitus } \\
\text { Other comorbidities }\end{array}$ & $4.2 \%$ & $1.4 \%$ & 0.620 \\
Fasting time (minutes) & $15.7 \%$ & $8.5 \%$ & 0.301 \\
$\begin{array}{l}\text { Use of atropine } \\
\text { Use of ephedrine }\end{array}$ & $1.4 \%$ & $10.0 \%$ & 0.063 \\
$\begin{array}{l}\text { Midazolam total dose (mg) } \\
\text { Duration of }\end{array}$ & $4.87 \pm 1.8$ & $4.8 \pm 2.0$ & 0.750 \\
anesthesia (minutes) & $95(80 / 111)$ & $90(80 / 105)$ & 0.242 \\
$\begin{array}{l}\text { Time in post-anesthesia } \\
\text { care unit (minutes) }\end{array}$ & $60(55 / 66)$ & $60(55 / 65)$ & 0.779 \\
\hline
\end{tabular}

Values are presented as median (1st and 3rd quartiles), mean $\pm S D$, or relative frequency (\%)

PONV postoperative nausea and vomiting

There were no significant differences in the incidence of PONV during the total, early, or late periods between the two groups. There was also no significant difference in the severity of nausea between the two groups. There was a significantly lower incidence of late-onset vomiting in the palonosetron group than in the ondansetron group; however, there was no significant difference in the overall incidence of vomiting or in the incidence of early-onset vomiting. The need for rescue medication for PONV and the total dose of metoclopramide was similar between the two groups (Table 2).

There were no significant differences in patient satisfaction with the management of PONV between the two groups (Table 3). The incidence of clinically significant PONV was low in both groups, as determined by the simplified PONV impact scale; however, there was no statistically significant difference in the incidence of clinically significant PONV between the two groups (Table 3) [13].

The degree of postoperative pain, the need for rescue i.v. morphine, and the cumulative consumption of rescue i.v. morphine were similar between the two groups (Table 4). No patient had symptoms suggestive of postdural puncture headache. The incidence of adverse effects potentially attributable to serotonin receptor antagonists, such as dizziness and headache, was low in both groups (no statistically significant difference was detected), and adverse effects were considered mild in all cases (data not shown).
Table 2 Frequencies of PONV and use of rescue medication in the ondansetron and palonosetron groups

\begin{tabular}{|c|c|c|c|}
\hline & Ondansetron & Palonosetron & $P$ value \\
\hline PONV & $52.9 \%$ & $42.9 \%$ & 0.236 \\
\hline Nausea & $51.4 \%$ & $42.9 \%$ & 0.310 \\
\hline Early-onset nausea & $27.1 \%$ & $21.4 \%$ & 0.430 \\
\hline Late-onset nausea & $35.7 \%$ & $30.0 \%$ & 0.472 \\
\hline Vomiting & $35.7 \%$ & $22.9 \%$ & 0.095 \\
\hline Early-onset vomiting & $20.0 \%$ & $14.3 \%$ & 0.370 \\
\hline Late vomiting $^{*}$ & $27.1 \%$ & $11.4 \%$ & 0.018 \\
\hline Use of rescue medication & $30.0 \%$ & $27.1 \%$ & 0.708 \\
\hline $\begin{array}{l}\text { Cumulative dose } \\
\text { of metoclopramide }(\mathrm{mg})^{*}\end{array}$ & $0(0 / 10)$ & $0(0 / 10)$ & 0.840 \\
\hline \multicolumn{4}{|c|}{$\begin{array}{l}\text { Early-onset regarded as } \leq 6 \mathrm{~h} \text { after surgery and late-onset regarded as } 6-48 \mathrm{~h} \\
\text { after surgery } \\
P O N V \text { postoperative nausea and vomiting } \\
\text { \#Presented as median ( } 1 \text { st and 3rd quartiles) } \\
{ }^{*} P<0.05\end{array}$} \\
\hline
\end{tabular}

\section{Discussion}

Several clinical trials have studied the efficacy of palonosetron in the management of PONV, and almost all of them have reported a beneficial role of palonosetron when compared to placebo or other $5 \mathrm{HT}-3$ receptor antagonists $[8,9,15-18]$. Two very recent meta-analyses showed reductions in the incidence of PONV when palonosetron was compared with ondansetron in patients who underwent general anesthesia $[11,12]$. To our knowledge, the current study is the first to compare palonosetron with ondansetron in patients at a high risk of PONV who received neuraxial anesthesia with intrathecal morphine.

In the current study, there was no statistically significant reduction in the overall incidence of $\mathrm{PONV}$ in patients who received palonosetron versus those who received ondansetron, which suggests that the prophylactic effect of palonosetron on PONV is similar to that of other $5 \mathrm{HT}$ 3 receptor antagonists in patients undergoing neuraxial anesthesia. However, we observed a significant reduction in the incidence of late-onset vomiting with palonosetron, which could be attributable to the longer duration of action of palonosetron. Thus, palonosetron may better attenuate the prolonged adverse effects of intrathecal morphine than shorter acting 5HT-3 receptor antagonists.

Table 3 Frequency of moderate/severe nausea, clinically significant PONV, and low patient satisfaction with PONV control

\begin{tabular}{llll}
\hline & Ondansetron & Palonosetron & $P$ value \\
\hline Moderate/severe nausea (VAS $\geq 5)$ & $44.2 \%$ & $35.7 \%$ & 0.301 \\
$\begin{array}{l}\text { Clinically significant } \\
\left.\text { PONV ( }{ }^{a} \text { score } \geq 5\right)\end{array}$ & $5.7 \%$ & $2.8 \%$ & 0.681 \\
$\begin{array}{l}\text { Low patient satisfaction } \\
\text { with PONV control }\end{array}$ & $15.7 \%$ & $10.0 \%$ & 0.313 \\
\hline
\end{tabular}

PONV control

PONV postoperative nausea and vomiting, VAS visual analog scale ${ }^{\text {a }}$ Simplified PONV impact scale [13] 
Table 4 Severity of pain, frequency of rescue analgesic use, and cumulative morphine consumption

\begin{tabular}{llll}
\hline & Ondansetron & Palonosetron & $P$ value \\
\hline Severity of pain (VAS) & $4(0 / 7)$ & $5(0 / 7)$ & 0.377 \\
Use of morphine & $5.7 \%$ & $8.6 \%$ & 0.745 \\
$\begin{array}{ll}\text { Cumulative morphine } \\
\text { consumption (mg) }\end{array}$ & $0(0 / 0)$ & $0(0 / 0)$ & 0.501 \\
\hline
\end{tabular}

VAS visual analog scale

${ }^{\text {a }}$ Presented as median (1st and 3rd quartile)

Few studies have focused on PONV in patients undergoing regional anesthesia with neuraxial opioids [5]. In a recent meta-analysis, 5HT-3 receptor antagonists (not including palonosetron) were shown to significantly reduce the incidence of PONV after caesarean section performed under spinal anesthesia with intrathecal morphine [19]. In the only study evaluating the efficacy of palonosetron after spinal anesthesia, palonosetron was associated with a lower incidence of PONV than ramosetron, another long-acting 5HT-3 receptor antagonist [10]. That study was performed in patients who underwent caesarean section without receiving neuraxial opioids; thus, the incidence of PONV and other pathophysiological considerations in that study may not be comparable to those of the current study.

Nausea and vomiting are well-known side effects of opioids that may have different central and peripheral components. The precise mechanisms of opioid-induced nausea and vomiting (OINV) are not entirely certain; however, known aspects include the activation of mu opioid receptors in the chemoreceptor trigger zone, direct stimulation of the vestibular apparatus, and peripheral action of opioids on the gastrointestinal tract [20]. The use of morphine in neuraxial anesthesia is related to a high incidence of PONV. Any hydrophilic substance (e.g., morphine), when injected into the subarachnoid space, tends to remain in the cerebrospinal fluid for a long period; during this period, it moves rostrally and reaches areas in the brainstem that induce nausea and vomiting [5].

It is likely that the addition of morphine in neuraxial anesthesia contributed to the high incidence of nausea and vomiting observed in this study. However, because several mechanisms and risk factors were involved (e.g., young age, female sex, a history of nonsmoking, and a history of gynecological surgery), it is difficult to clearly separate "pure" OINV from the broader definition of PONV.

The underlying pathophysiological mechanisms of PONV after neuraxial anesthesia include the use of hydrophilic opioids, arterial hypotension, increased sensory blockade, symptomatic liquoric hypotension, and gastrointestinal hyperactivity due to sympathetic blockade [5]. Serotonin receptor antagonists may only counteract some of these factors. Therefore, other strategies for PONV prevention must be used in some cases.
Dexamethasone is an effective drug for PONV prophylaxis, including in patients who receive neuraxial opioids [21]. The combination of dexamethasone and ondansetron has been shown to be particularly effective in patients at high risk of PONV [22]. Moreover, it has recently been reported that the combination of dexamethasone and palonosetron is more effective than palonosetron alone for reducing PONV after laparoscopic surgery [23].

Considering the high incidence of PONV in our study population, we believed it was ethically appropriate to use a combination therapy for PONV prevention rather than a single drug [1]. As patients in both groups received dexamethasone for this purpose, the overall incidence of PONV was probably diminished, which may have increased the chance of a type II error and reduced the detection power of this study. A similar limitation is applicable to secondary outcomes, such as the incidence of clinically significant PONV as determined by the simplified PONV impact scale. Notably, the incidences of clinically significant PONV were low in both groups.

The long-acting effect of palonosetron seems to be useful when a hydrophilic opioid, such as morphine, is administered intrathecally. However, despite the pharmacological benefits of palonosetron, the incidence of PONV remained high in the current study. Further studies are necessary to evaluate the role of palonosetron in the prevention of PONV in patients who undergo neuraxial anesthesia, particularly when a neuraxial opioid is used. It is also important to study the role of palonosetron in association with other PONV prophylaxis strategies.

\section{Conclusion}

In conclusion, palonosetron exhibited efficacy similar to that of ondansetron for reducing the overall incidence of PONV in patients who underwent TAH under spinal anesthesia with intrathecal morphine; however, palonosetron did reduce the incidence of late-onset vomiting better than ondansetron.

\section{Abbreviations}

OINV: Opioid-induced nausea and vomiting; PONV: Postoperative nausea and vomiting; TAH: Total abdominal hysterectomy; VAS: Visual analogue scale

\section{Acknowledgements \\ None.}

\section{Authors' contributions \\ Study design: GOC, RLA, CNL, PRRO, NSPM. Data collection: GOC, GNJ, JCMFOJr, PRRO, CNL. Data analysis: GOC, RLA, MJM, LSCA. Drafting paper: GOC, RLA, MJM, LJSCA, NSPM. The manuscript was reviewed and approved by all the authors.}

\section{Funding}

This research did not receive any specific grant from funding agencies in the public, commercial, or not-for-profit sectors. 


\section{Availability of data and materials}

The datasets used and/or analyzed during the current study are available from the corresponding author on reasonable request.

\section{Ethics approval and consent to participate}

This study was approved by the Research Ethics Committee of São Rafael Hospital (reference number: 1.238.882/2015, Chairperson Prof. Regina M. P. Oliveira, January 7th 2015). All the patients gave written informed consent prior to study enrollment.

\section{Consent for publication}

Not applicable.

\section{Competing interests}

The authors declare that they have no conflicts of interest.

\section{Author details}

'Department of Anesthesiology, São Rafael Hospital, D'Or Institute for Research and Education (IDOR), Salvador, Brazil. ${ }^{2}$ Department of Anesthesiology, Cardiopulmonar Hospital, Salvador, Brazil. ${ }^{3}$ Department of Anesthesiology, São Paulo State University, Botucatu, Brazil. ${ }^{4}$ Federal University of Bahia, Salvador, Brazil. ${ }^{5}$ Department of Gynecology, São Rafael Hospital, D'Or Institute for Research and Education (IDOR), Salvador, Brazil. ${ }^{6}$ Department of Anesthesiology, Santo Antonio Hospital, Salvador, Brazil.

Received: 3 February 2019 Accepted: 11 August 2019

Published online: 17 August 2019

\section{References}

1. Gan TJ, Diemunsch P, Habib AS, Kovac A, Kranke P, Meyer TA, Watcha M, Chung F, Angus S, Apfel CC, Bergese SD, Candiotti KA, Chan MT, Davis PJ, Hooper VD, Lagoo-Deenadayalan S, Myles P, Nezat G, Philip BK, Tramer MR. Society for Ambulatory Anesthesia. Consensus guidelines for the management of postoperative nausea and vomiting. Anesth Analg. 2014; 118:85-113.

2. Catro-Alves LJ, De Azevedo VL, De Freitas Braga TF, Goncalves AC, De Oliveira GS Jr. The effect of neuraxial versus general anesthesia techniques on postoperative quality of recovery and analgesia after abdominal hysterectomy: a prospective, randomized, controlled trial. Anesth Analg. 2011;113:1480-6.

3. Chinachoti T, Nilrat P, Samarnpiboonphol P. Nausea, vomiting and pruritus induced by intrathecal morphine. J Med Assoc Thail. 2013;96:589-94.

4. Apfel CC, Heidrich FM, Jukar-Rao S, Jalota L, Hornuss C, Whelan RP, Zhang K, Cakmakkaya OS. Evidence-based analysis of risk factors for postoperative nausea and vomiting. Br J Anaesth. 2012;109:742-53.

5. Borgeat A, Ekatodramis G, Schenker CA. Postoperative nausea and vomiting in regional anesthesia: a review. Anesthesiology. 2003;98:530-47.

6. Chandrakantan A, Glass PS. Multimodal therapies for postoperative nausea and vomiting, and pain. Br J Anaesth. 2011;107:i27-40.

7. Dominguez JE, Habib AS. Prophylaxis and treatment of the side-effects of neuraxial morphine analgesia following cesarean delivery. Curr Opin Anaesthesiol. 2013;26:288-95.

8. Kovac AL, Eberhart L, Kotarski J, Clerici G, Apfel C. A randomized, doubleblind study to evaluate the efficacy and safety of three different doses of palonosetron versus placebo in preventing postoperative nausea and vomiting over a 72-hour period. Anesth Analg. 2008;107:439-44.

9. Candiotti KA, Kovac AL, Melson TI, Clerici G, Joo Gan T. A randomized, double-blind study to evaluate the efficacy and safety of three different doses of palonosetron versus placebo for preventing postoperative nausea and vomiting. Anesth Analg. 2008;107:445-51.

10. Chattopadhyay S, Goswami S. Palonosetron versus ramosetron prophylaxis for control ofpostoperative nausea and vomiting after cesarean delivery under spinal anesthesia. J Obstet Gynaecol India. 2015;65:28-33.

11. Xiong C, Liu G, Ma R, Xue J, Wu A. Efficacy of palonosetron for preventing postoperative nausea and vomiting: a systematic review and meta-analysis. Can J Anaesth. 2015;62:1268-78.

12. Singh PM, Borle A, Gouda D, Makkar JK, Arora MK, Trikha A, Sinha A, Goudra B. Efficacy of palonosetron in postoperative nausea and vomiting (PONV)-a meta-analysis. J Clin Anesth. 2016;34:459-82.

13. Myles PS, Wengritzky R. Simplified postoperative nausea and vomiting impact scale for audit and post-discharge review. Br J Anaesth. 2012;108:423-9.
14. Apfel CC, Roewer N, Korttila K. How to study postoperative nausea and vomiting. Acta Anaesthesiol Scand. 2002;46:921-8.

15. Park SK, Cho EJ. A randomized, double-blind trial of palonosetron compared with ondansetron in preventing postoperative nausea and vomiting after gynaecological laparoscopic surgery. J Int Med Res. 2011;39:399-407.

16. Moon YE, Joo J, Kim JE, Lee Y. Anti-emetic effect of ondansetron and palonosetron in thyroidectomy: a prospective, randomized, double-blind study. Br J Anaesth. 2012;108:417-22.

17. Kim SH, Hong JY, Kim WO, Kil HK, Karm MH, Hwang JH. Palonosetron has superior prophylactic antiemetic efficacy compared with ondansetron or ramosetron in high-risk patients undergoing laparoscopic surgery: a prospective, randomized, double-blinded study. Korean J Anesthesiol. 2013; 64:517-23.

18. Chun HR, Jeon IS, Park SY, Lee SJ, Kang SH, Kim SI. Efficacy of palonosetron for the prevention of postoperative nausea and vomiting: a randomized, double-blinded, placebo-controlled trial. Br J Anaesth. 2014;112:485-90.

19. George RB, Allen TK, Habib AS. Serotonin receptor antagonists for the prevention and treatment of pruritus, nausea, and vomiting in women undergoing cesarean delivery with intrathecal morphine: a systematic review and meta-analysis. Anesth Analg. 2009;109:174-82.

20. Smith HS, Laufer A. Opioid induced nausea and vomiting. Eur J Pharmacol. 2014:722:67-78.

21. Allen TK, Jones CA, Habib AS. Dexamethasone for the prophylaxis of postoperative nausea and vomiting associated with neuraxial morphine administration: a systematic review and meta-analysis. Anesth Analg. 2012; 114:813-22.

22. Apfel CC, Korttila K, Abdalla M, Kerger H, Turan A, Vedder I, Zernak C, Danner K, Jokela R, Pocock SJ, Trenkler S, Kredel M, Biedler A, Sessler DI, Roewer $\mathrm{N}$, investigators IMPACT. A factorial trial of six interventions for the prevention of postoperative nausea and vomiting. N Engl J Med. 2004;350: 2441-51.

23. Bala I, Bharti N, Murugesan S, Gupta R. Comparison of palonosetron with palonosetron-dexamethasone combination for prevention of postoperative nausea and vomiting in patients undergoing laparoscopic cholecystectomy. Minerva Anestesiol. 2014;80:779-84

\section{Publisher's Note}

Springer Nature remains neutral with regard to jurisdictional claims in published maps and institutional affiliations.

Ready to submit your research? Choose BMC and benefit from:

- fast, convenient online submission

- thorough peer review by experienced researchers in your field

- rapid publication on acceptance

- support for research data, including large and complex data types

- gold Open Access which fosters wider collaboration and increased citations

- maximum visibility for your research: over $100 \mathrm{M}$ website views per year

At $\mathrm{BMC}$, research is always in progress.

Learn more biomedcentral.com/submissions 